\title{
Equilibrium and Kinetic Study of Bovine Serum Albumin (BSA) Adsorption onto Fabricated Polyethersulfone (PES)/Hydroxyapatite (HAP) Adsorptive Mixed Matrix Membrane (MMM)
}

\author{
Abdul Latif Ahmad, ${ }^{1 *}$ Noor Fazliani Shoparwe ${ }^{2}$ and N. H. E. Hanifa ${ }^{1}$ \\ ${ }^{1}$ School of Chemical Engineering, Universiti Sains Malaysia, \\ Engineering Campus, 14300 Nibong Tebal, Pulau Pinang, Malaysia \\ ${ }^{2}$ Faculty of Bioengineering and Technology, Universiti Malaysia Kelantan, \\ Jeli Campus, 17600 Jeli, Kelantan, Malaysia
}

Published online: 15 February 2019

To cite this article: Ahmad, A. L., Shoparwe, N. F. \& Hanifa, N. H. E. (2019). Equilibrium and kinetic study of bovine serum albumin (BSA) adsorption onto fabricated polyethersulfone (PES)/hydroxyapatite (HAP) adsorptive mixed matrix membrane (MMM). J. Phys. Sci., 30(Supp. 1), 43-63, https://doi.org/10.21315/jps2019.30.s1.3

To link to this article: https://doi.org/10.21315/jps2019.30.s1.3

\begin{abstract}
In this study, different amount of hydroxyapatite (HAP) was embedded into polyethersulfone (PES) matrix to prepare adsorptive mixed matrix membranes (MMMs). All fabricated membranes were characterised based on functional groups, morphology, overall porosity, water content, hydrophilicity and pure water flux. The relationship of equilibrium and kinetics of bovine serum albumin (BSA) adsorption onto fabricated membrane in a batch system was performed. The BSA adsorption equilibrium data is best described by Freundlich isotherm model followed by Langmuir isotherm model. The kinetics of the adsorption is well presented by pseudo-second-order kinetic model and followed by pseudo-first-order kinetic model. Among all membranes, fabricated PES/ HAP adsorptive MMM (K4) produced with $60 \mathrm{wt} \%$ HAP shows the best characteristic of membrane with higher water content, porosity and hydrophilicity, demonstrating the higher average pure water flux, $j_{w}$ of $29.12 \mathrm{~m}^{2} \mathrm{l}^{-1} \mathrm{~h}^{-1} \pm 0.6 \mathrm{~m}^{2} \mathrm{l}^{-1} \mathrm{~h}^{-1}$, adsorption capacity, $q_{e}$ of 26.54 ( $g$ BSA.g membrane $\left.e^{-1}\right)$ and adsorption kinetic rate, $k_{2}$ of $0.814\left(h^{-1}\right)$. The reusability of $K 4$ membrane shows the most effective regeneration compare than other membrane. The results suggested that the PES/HAP adsorptive MMM can be effectively applied for the adsorption of BSA from aqueous solution and can offer high potential merit for application in membrane adsorption process.
\end{abstract}

Keywords: Hydroxyapatite, bovine serum albumin, mixed matrix membrane, equilibrium isotherm, kinetic 


\section{INTRODUCTION}

Protein separation by packed column chromatography is commonly used in downstream processing. ${ }^{1,2}$ However, packed column chromatography still has limitations that includes high pressure drop, relatively slow intra-bead mass transport, difficulty in column packing and complications in scale-up procedures. ${ }^{3-5}$ Furthermore, this method requires long process time and bed compression, and clogging might occur due to low bed porosity and long bed height. ${ }^{6}$ Therefore, these limitations have led to the development of membrane chromatography using polymeric membrane for the separation and fractionation of protein. ${ }^{7-12}$ Currently, adsorptive membrane has gained more attention for separation of protein because it offers several advantages such as excellent removal efficiency, higher flow rate, lower pressure drop, reusability and ease of scaling up., ${ }^{8,913-17}$ Adsorptive MMM is a type of membrane formed by incorporating fillers in polymer matrix. ${ }^{8}$ This can be done by integrating inorganic filler such as ion exchange resin and nanoparticles such as carbon nanotube, $\mathrm{ZnO}$ and $\mathrm{TiO}_{2}$ into the polymeric membrane..$^{13,15,18-22}$

In recent time, significant efforts have been devoted in fabrication of polymeric MMM by using hydroxyapatite (HAP) as great potential filler for separation of protein. ${ }^{23-27}$ HAP (chemical formula $\left.\mathrm{Ca}_{10}\left(\mathrm{PO}_{4}\right)_{6}(\mathrm{OH})_{2}\right)$ is inorganic component of the hard tissues in bones. ${ }^{28}$ HAP is usually observed to be carbonate-substituted and calcium-deficient. ${ }^{29}$ HAP has successfully been applied in separation of proteins, enzymes, nuclei acid, virus and other biological molecules. ${ }^{30-34}$ It has been proven that electrostatic interaction between calcium ion in $\mathrm{HAP}$ and $\mathrm{COOH}^{-}$ group of bovine serum albumin (BSA) is the dominating factor in adsorption process. $^{30,31}$ Since there has been a limited number of studies reported on used HAP for adsorptive MMM, this research is carried out to study the effect of different compositions of HAP embedded with PES matrix to adsorb BSA in a batch system. ${ }^{23-25,27}$ The effect of different amounts of HAP to the structure and properties of the fabricated membrane was also evaluated. Adsorption equilibrium and kinetic studies have also been performed to understand the process of BSA adsorption onto fabricated membrane. Adsorption equilibrium and kinetic data are fitted using different models and parameters value were evaluated.

\section{EXPERIMENTAL}

\subsection{Materials}

The polymeric membrane material, polyethersulfone (PES Ultrason E6020P with $\mathrm{M}_{\mathrm{W}}=58,000 \mathrm{~g} \mathrm{~mol}^{-1}$ ) was purchased from BASF. Hydroxyapatite (HAP), solvent N.N-dimethylacetamide (DMAc) and BSA (molecular weight $69 \mathrm{kDa}$ ) were 
purchased from Sigma Aldrich (United States). Deionised water was used for all the experiments.

\subsection{Membrane Preparation}

The polymeric membranes were prepared by dry-wet phase inversion method. PES/DMAc was maintained at same weight ratio while composition of HAP was varied based on percentage to PES weight as shown in Table 1. In detail, the PES was dried in a vacuum oven at $70^{\circ} \mathrm{C}$ for $24 \mathrm{~h}$ in order to remove moisture. A dope solution was first prepared by dissolving the calculated amount of HAP in DMAc solvent by using magnetic stirrer for $6 \mathrm{~h}$. The HAP suspension was then sonicated using ultarasonicator batch (Elmasonic $\mathrm{S} 80 \mathrm{H}$ ) for $3 \mathrm{~h}$ to produce homogeneous solution and well-dispersed HAP particles. Subsequently, PES was added slowly into the solution. The resulting dope solution was stirred at $60^{\circ} \mathrm{C}$, with speed $500 \mathrm{rpm}$ for $24 \mathrm{~h}$. The final mixture of casting solution was degassed using ultrasonic bath for $3 \mathrm{~h}$ in order to completely remove air bubbles from the solution. The solution was cast on a smooth glass plate at a room temperature. Before casting process, the glass plate was wiped with acetone to remove the impurities, and to make sure the glass is clean. Each polymeric solution was cast with a casting machine filmograph (K4340 automatic Film Applicator, Elcometer) with a thickness of $300 \mu \mathrm{m}$. Thereafter, the membranes were exposed to air for $30 \mathrm{~min}$ before being immersed in distilled water at $20^{\circ} \mathrm{C}$ and left for $24 \mathrm{~h}$ to allow for precipitation. Drying was subsequently done for $24 \mathrm{~h}$ before characterising the membrane. The final thickness of fabricated membranes was measured by a digital micrometre.

Table 1: Composition of casting solution.

\begin{tabular}{cccc}
\hline Membrane & PES (wt\%) & DMAc (wt\%) & $\begin{array}{c}\text { HAP (wt\%) } \\
\text { (Based on percentage to PES weight) }\end{array}$ \\
\hline K0 & 16 & 84 & 0 \\
K1 & 16 & 84 & 10 \\
K2 & 16 & 84 & 20 \\
K3 & 16 & 84 & 40 \\
K4 & 16 & 84 & 60 \\
K5 & 16 & 84 & 80 \\
\hline
\end{tabular}




\subsection{Membranes Characterisation}

\subsubsection{Chemical properties of the fabricated membrane}

The chemical properties of fabricated membranes were analysed by Fourier transform infrared (FTIR) spectrometer. The spectra analysis was performed in determination of functional groups of the fabricated membranes. The fabricated membranes also were analysed before and after adsorption process in order to observe that there were BSA ions binding at the surfaces of membranes samples. An FTIR spectrometer (NICOLEST iS10, USA) was employed for this purpose.

\subsubsection{Morphology of the fabricated membrane}

The top and cross-section of the fabricated membranes were characterised by SEM using a HITACHI Tabletop Microscope instrument (TM-3000-Japan) operated at $20 \mathrm{kV}$. Membrane samples were cut into small sizes and mounted on a double-sided carbon adhesive foil as the sample holder. Prior to the SEM test, sputtered coating was used (Quorum-SC7620) to coat the membrane surface and cross-sectional area with a thin layer of gold under vacuum to avoid the effect of electrostatic charging.

\subsubsection{Hydrophilicity of the fabricated membrane}

The surface hydrophilicity of fabricated membranes was characterised using the contact angle goniometer (Model: OCA15plus, DataPhysics). A water droplet $(1 \mu l)$ was deposited onto each membrane surface through a needle tip attached to the goniometer. A magnified image of water droplet was observed by a digital camera and the CA readings were obtained $10 \mathrm{~s}$ after the water drop deposited on the membrane surface. The contact angles of each membrane at 5 different locations were recorded and their mean values were calculated.

\subsubsection{Water content of the fabricated membrane}

Water content of fabricated membranes were measured by immersing membrane sample in deionised water for $24 \mathrm{~h}$. The dried membranes were cut off into a rectangular shape with dimension of $9 \mathrm{~cm} \times 1 \mathrm{~cm}$. After $24 \mathrm{~h}$, the excess water of the membrane samples was removed by filter paper. The weights of wet membranes were measured. The membrane samples were then dried in a vacuum oven at $60^{\circ} \mathrm{C}$ for $24 \mathrm{~h}$ and weight of dry membrane was measured after completion of drying. The percentage of water content was calculated by using Equation 1:35

$$
\text { Water content }(\%)=\frac{W_{w}-W_{d}}{W_{d}} \times 100
$$

where $W_{w}$ and $W_{d}$ are the weight of wet and dry membranes (g). 


\subsubsection{Porosity of the fabricated membrane}

The porosity of membranes was measured by immersing the membrane sample in deionised water for $24 \mathrm{~h}$. The dried membranes were cut into rectangular shape with dimensions of $9 \mathrm{~cm} \times 1 \mathrm{~cm}$. Thereafter, the excess water of the membrane samples were removed using filter paper and the thickness of the wet membrane was determined by a digital micrometre (Mitotoyo, Japan). The surface area and weights of wet membranes were measured. The membrane samples were then dried in vacuum oven at $60^{\circ} \mathrm{C}$ for $24 \mathrm{~h}$ and weight of dry membrane was measured after drying was completed. The membrane porosity $\left(P_{r}\right)$ was calculated using Equation $2: 35$

$$
P_{r}=\frac{W_{w}-W_{d}}{d_{w} \times S \times l}
$$

where $W_{w}$ and $W_{d}$ are the weight of wet and dry membranes (g), $S$ is the membrane area $\left(\mathrm{cm}^{2}\right), l$ is the thickness of wet membrane $(\mathrm{cm})$ and $d_{w}$ is water density at room temperature $\left(1 \mathrm{~g} \mathrm{~cm}^{-3}\right)$.

\subsection{Separation Test}

Membrane permeability was carried out using high-pressure dead-end filtration cell, Sterlitech HP4750 (Sterlitech Corporation, Washington, United States) with an active surface area of $14.6 \mathrm{~cm}^{2}$. The fabricated membrane was compressed at 5 bar using deionised water for about $1 \mathrm{~h}$ to minimise compaction effects. The experiment was conducted for pure water at 3 bar and the pure water flux (PWF) was recorded with time. The pure water flux was calculated using Equation 3:

$$
J w=\frac{Q}{A \triangle t}
$$

where $J w$ is pure water flux $\left(1 \mathrm{~m}^{-2} \mathrm{~h}^{-1}\right), Q$ is the quantity of permeate collected $\left(\mathrm{m}^{3}\right)$, $\triangle t$ is the sampling time (h) and $A$ is the area of membrane $\left(\mathrm{m}^{2}\right)$.

\subsection{Adsorption and Regeneration Studies}

The static adsorption experiments of BSA on fabricated PES/HAP adsorptive MMM were carried out in a batch system. The membrane samples were cut into a rectangular shape with the dimensions of $2 \mathrm{~cm} \times 1 \mathrm{~cm}$ and weighed. The membrane samples were then incubated in $5 \mathrm{ml}$ of BSA solutions prepared at various concentrations, under continuous shaking ( $90 \mathrm{rpm}$ ) for $24 \mathrm{~h}$ at room temperature. The effect of initial BSA concentrations on the adsorption onto fabricated membrane was investigated in the range of $0.0-2.0 \mathrm{mg} \mathrm{ml}^{-1}$ at $\mathrm{pH}$ buffer solution of 5.4. ${ }^{23}$ The concentration of BSA was determined by using 
UV-visible spectrophotometer (Mode Shimadzu UV-1700, Japan) at wavelength $280 \mathrm{~nm}$ with $10 \mathrm{~mm}$ quartz cuvettes.

The kinetics adsorption of BSA on fabricated PES/HAP adsorptive MMM was investigated at room temperature $\left(25^{\circ} \mathrm{C} \pm 1{ }^{\circ} \mathrm{C}\right), \mathrm{pH}$ of 5.4 and initial BSA concentration of $2.0 \mathrm{mg} \mathrm{ml}^{-1}$ for all the fabricated membranes. The final concentration of BSA was measured for every $1 \mathrm{~h}$ until the equilibrium state was reached. The concentration was monitored by using UV-VIS spectrophotometer at $560 \mathrm{~nm}$ with $10 \mathrm{~mm}$ quartz cuvettes. The amount of BSA adsorbed per unit mass of membrane, $q_{e}$ was calculated on the basis of the mass balance Equation 4:

$$
\text { BSA adsorption, } q_{e}\left(m_{B S A} \cdot g^{-1}{ }_{\text {membrane }}\right)=\frac{\left(C_{i}-C_{f}-V\right)}{1000 \times W}
$$

where $q_{e}$ is the amount of BSA adsorbed on the membrane $\left(\mathrm{mg} \mathrm{g}^{-1}\right), C_{i}$ and $C_{f}$ are the initial and final concentrations of BSA, $V(\mathrm{ml})$ is the volume of initial solution and $W(g)$ is the weight of membrane used. After kinetics adsorption experiment, the used membranes were desorbed in acetate buffer solution for $24 \mathrm{~h}$ by continuous shaking $(90 \mathrm{rpm})$ at room temperature. The membranes were then reused for another cycle of BSA adsorption. The adsorption capacity of regenerated membranes was investigated to observe the reduction in adsorption capacity. Three adsorption/regeneration cycles were conducted to evaluate the reusability of the membranes. Triplicates experiments were carried out for the system studied to get a mean value.

\subsection{Adsorption Equilibrium and Kinetics Study}

\subsubsection{Adsorption isotherm model}

Adsorption isotherms are used to describe the equilibrium of the BSA between the aqueous solution and the membrane phase. Depending on the nature of the adsorption system, the isotherm model may determine the maximum adsorption capacity and parameters that can be used for a better understanding of the binding mechanism. ${ }^{36}$ The BSA adsorption isotherms data at different HAP loading in the fabricated membrane were analysed using Langmuir and Freundlich equations. Langmuir equation is based on the theoretical model and assumes that the maximum adsorption correspond to a monolayer sorption of a solute from a liquid solution. ${ }^{37}$ The Langmuir equation is given as: ${ }^{38}$

$$
q_{e q}=\frac{q_{m} K_{D} C_{e q}}{1+K_{D}+C_{e q}}
$$


Freundlich isotherm model is an empirical equation based on sorption on a heterogeneous surface or surface supporting sites of varied affinities. It is assumed that the stronger binding sites are occupied first and the binding strength decreases with the increasing degree of site occupation. ${ }^{39}$ Freundlich isotherm model is represented as Equation 6:

$$
q_{e q}=K_{F} C_{e q}^{1 / n}
$$

where $q_{e q}$ is the equilibrium adsorbed amount of BSA on the membrane $\left(\mathrm{g} \mathrm{g}^{-1}\right), \mathrm{V}$ is the volume of the solution, $C_{0}$ and $C_{e q}$ are the initial and equilibrium concentrations of BSA $\left(\mathrm{g} \mathrm{l}^{-1}\right), q_{m}$ is the maximum adsorption capacity of BSA corresponding to the membrane saturation $\left(\mathrm{g} \mathrm{l}^{-1}\right), \mathrm{)}, 1 / n$ gives an idea of the grade of heterogeneity, and $K_{D}$ is equilibrium constant $\left(1 \mathrm{~g}^{-1}\right)$. The non-linear least-squares regression of Lavenberg-Maquadrt method using Polymath@ Version 6.10 (CACHE Corp, USA) was employed in order to estimate the value of parameters adsorption isotherm model.

\subsubsection{Adsorption kinetic model}

The kinetic of adsorption is very important in understanding the insight of the sorption mechanism and the potential rate controlling step such as mass transport and chemical reaction process. ${ }^{40}$ Various kinetic models were proposed to test the experimental data including pseudo-first and pseudo-second order kinetic model to predict the adsorption kinetics. Pseudo first order model can be defined as:

$$
\frac{d q}{d t}=k_{1}\left(q_{e}-q\right)
$$

Integrating Equation 7 with respect to boundary conditions $q=0$ at $t=0$ and $q=q_{t}$ at $t=t$ yields:

$$
\ln \left(q_{e}-q_{t}\right)=\ln \left(q_{e}\right)-k_{1} t
$$

where $q_{\mathrm{e}}$ and $q_{t}$ are the amounts of adsorbed BSA $\left(\mathrm{mg} \mathrm{g}^{-1}\right)$ on the fabricated adsorptive MMM at equilibrium and at time $t(\mathrm{~h})$ and $k_{1}\left(\mathrm{~h}^{-1}\right)$ is the first-order adsorption rate constant. The plot of $\ln \left(q_{e}-q_{t}\right)$ versus $t$ gives the slope of $k_{1}$ and intercept of $\ln \left(q_{e}\right)$. However, in many cases, the pseudo-second order kinetic model does not fit well in the whole range of contact time and is generally applicable over the initial stage of adsorption processes. ${ }^{41}$ 
Contrary to the pseudo-first order kinetic model, the pseudo second-order equation predicts the behaviour over the whole range of adsorption and is in agreement with an adsorption mechanism being the rate of controlling step. The pseudo secondorder model based on equilibrium adsorption is expressed as: ${ }^{41}$

$$
\frac{d q}{d t}=k_{2}\left(q_{e}-q\right)^{2}
$$

Separating the variables Equation 9 gives:

$$
\frac{d q}{\left(q_{e}-q\right)}=k_{2} t
$$

Integrating Equation 10 with respect to boundary conditions $q=0$ at $t=0$ and $q=q_{t}$ at $t=t$, yields:

$$
\frac{t}{q}=\frac{1}{k_{2} q_{e}^{2}}+\frac{1}{q_{e}} t
$$

where $k_{2}$ is the rate constant of second-order BSA adsorption $\left(\mathrm{g} \mathrm{g}^{-1} \mathrm{~h}^{-1}\right)$, and $q_{e}$ is the adsorption capacity calculated by the pseudo-second order kinetic model $\left(\mathrm{mg} \mathrm{g}^{-1}\right)$. The linear plot of $t / q_{t}$ versus $\mathrm{t}$ gives $1 / q_{e}$ as the slope and $1 / k_{2} q_{e}^{2}$ as the intercept.

\subsubsection{The statistical analysis}

The suitability of the isotherm and kinetic model to the experimental data was compared by the values of the correlation coefficients, $R^{2}$. The higher of $R^{2}$ (closer to one) represents the best fit. Furthermore, the models were evaluated according to the mean square error (RMSE). The RMSE value was calculated by the sum squares errors divided by the length of actual data represented as:

$$
R M S E=\sqrt{\frac{\sum\left(f_{i}-y_{i}\right)^{2}}{n_{t}}}
$$

where $f_{i}, y_{i}$ and $n_{t}$ are the model data, experimental data and length of actual data, respectively.

\section{RESULTS AND DISCUSSION}

\subsection{Chemical Properties of Fabricated Membranes}

The fabricated membranes were characterised using attenuated total reflectanceFourier transform infrared spectroscopy (ATR-FTIR). Figure 1 shows the ATR-FTIR band vibration data on (a) HAP particle, (b) neat PES membrane, 
(c) PES/HAP adsorptive MMM and (d) PES/HAP adsorptive MMM after adsorption of BSA, respectively. All the fabricated membranes contain the absorption peaks of PES structure which includes a benzene ring $\mathrm{C}=\mathrm{C}$ stretching vibration at $1578 \mathrm{~cm}^{-1}$ and $1486 \mathrm{~cm}^{-1}$, an aromatic ether band at around $1235 \mathrm{~cm}^{-1}$ and a sulphone group structure at $837.0 \mathrm{~cm}^{-1}, 1111.68 \mathrm{~cm}^{-1}$ and $1144.56 \mathrm{~cm}^{-1}$. ${ }^{42}$ Absorption band corresponding to $\mathrm{PO}_{4}{ }^{3-}$ groups was observed at $1011.0 \mathrm{~cm}^{-1}$ and $1648.0 \mathrm{~cm}^{-1}$ due to the chemical properties of HAP. ${ }^{43}$ The peaks at around $3316 \mathrm{~cm}^{-1}$ is assigned to adsorbed water. The peak obviously appeared after BSA adsorption onto PES/HAP adsorptive MMM due to overlapping with the broad band of adsorbed water, arises from the hydroxyl group in BSA. ${ }^{30}$ The result shows that all these functional groups were involved in BSA adsorption on PES/HAP adsorptive MMM.

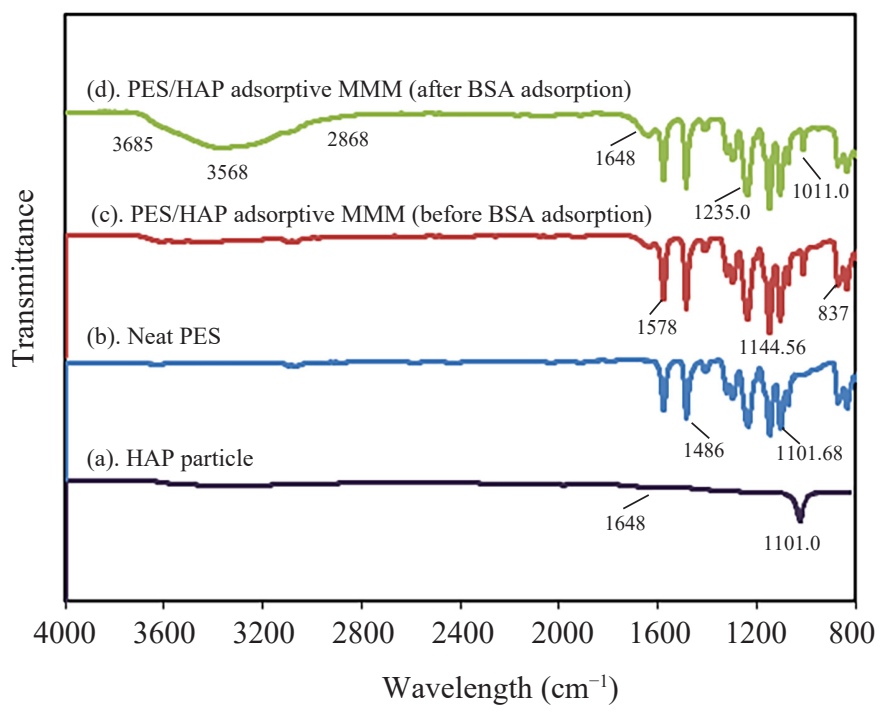

Figure 1: FTIR spectra for (a) HAP particles, (b) neat PES membrane, (c) PES/HAP MMM and (d) PES/HAP MMM after BSA adsorption.

\subsection{Morphology of Fabricated Membranes}

The SEM analysis was used to characterise the top surface (Figure 2) and crosssection (Figure 3 ) of all the fabricated membranes. The obtained image confirms that circular pore and interconnected porous structure can be easily observed throughout the membrane. During the phase inversion, HAP particle was entrapped within the PES matrix. Distinguish white spot indicated HAP particle in K1, K2, K3, K4 and K5 membranes. The addition of different amounts of HAP particle into the PES matrix significantly altered the morphology of fabricated membrane. 
By increasing the HAP loading from $10 \%$ to $80 \%$, the membrane heterogeneity improves which increases the voids and cavities throughout the membrane matrix. This also leads to pore filling by HAP particle especially at high loading of HAP particle. The relation of membrane structure to water content, porosity, hydrophilicity, pure water flux and BSA adsorption behaviour will be discussed in the next section.
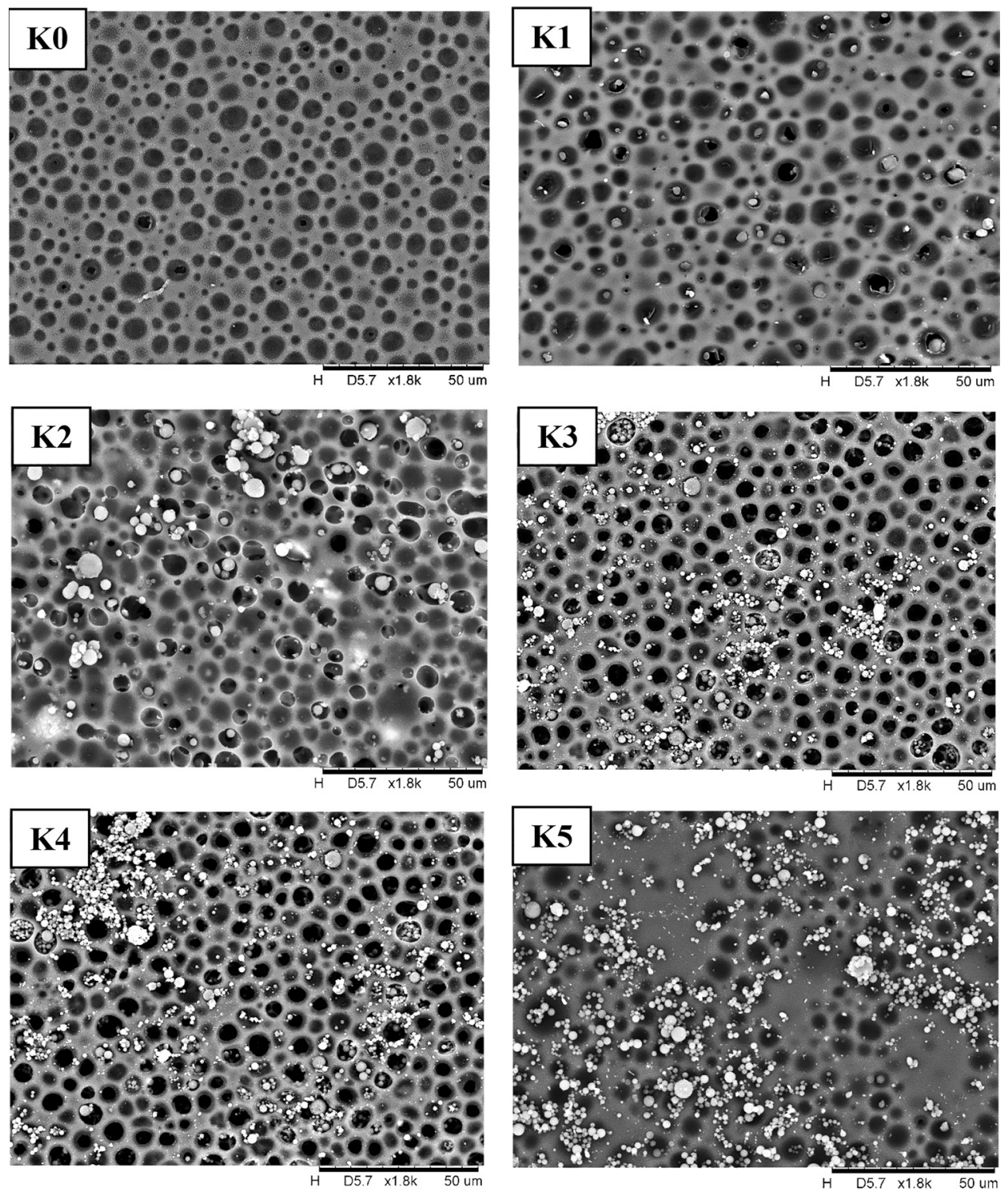

Figure 2: SEM micrograph of top surface for K0, K1, K2, K3, K4 and K5 membranes. 

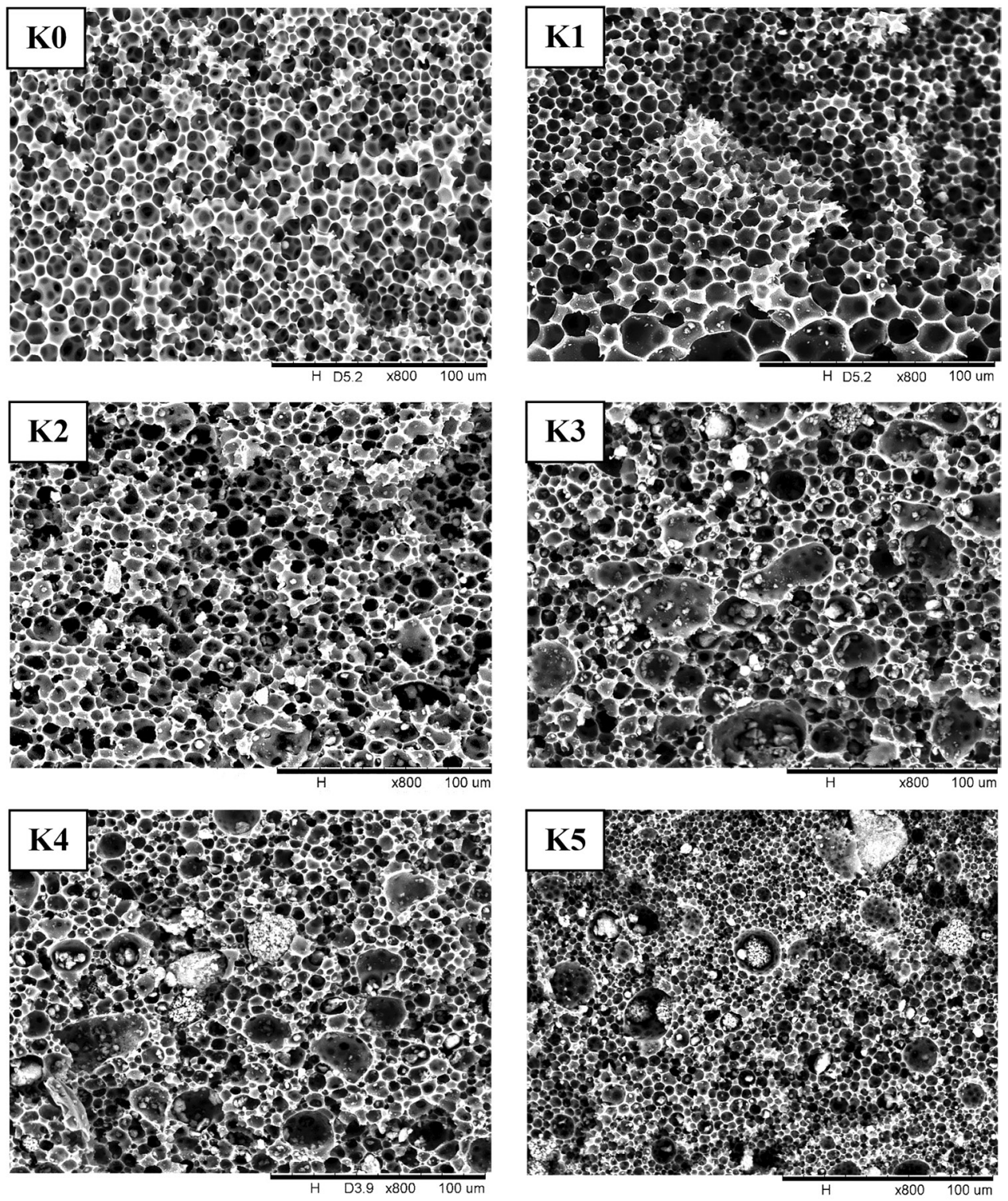

Figure 3: SEM micrograph of cross section for K0, K1, K2, K3, K4 and K5 membranes. 


\subsection{Final Thickness, Water Content, Overall Porosity, Water Contact Angle and Pure Water Flux}

Membrane final thickness, water content, overall porosity, water contact angle and pure water flux of the fabricated membranes are shown in Table 2. As shown in Table 2, membrane thickness follows the sequence of $\mathrm{K} 5>\mathrm{K} 4>\mathrm{K} 3>\mathrm{K} 2>$ $\mathrm{K} 1>\mathrm{K} 0$. The results show that membrane thickness increases with increase in HAP loading. This increasing factor might be caused by the entrapment of solid content in the fabricated PES/HAP adsorptive MMM. The results in Table 2 show that the increment of HAP loading from $0 \mathrm{wt} \%$ up to $60 \mathrm{wt} \%$ in the casting solution also led to an improvement in membrane water content and overall porosity of fabricated membrane. However, there are a slightly reduction of these characteristics at $80 \mathrm{wt} \%$ of HAP loading. This is because the amount of voids and cavities available might have been reduced and occupied by HAP particles which reduced the water adsorption. The structure of the membrane was also giving significant effect on hydrophilicity and the pure water flux. As shown in Table 2, the measured values of contact angle of synthesised membrane follow the sequence of $\mathrm{K} 0>\mathrm{K} 1>\mathrm{K} 2>\mathrm{K} 3>\mathrm{K} 5>\mathrm{K} 4$. The neat PES (K0) displayed the largest contact angle due the hydrophobic properties of PES raw materials. The presence of HAP in the fabricated membrane gave synergetic effects to the membrane structure and directly improves the hydrophilicity and pure water flux of the membrane.

Table 2: Overall membrane thickness, water content, porosity and contact angle and average water flux of $\mathrm{K} 0, \mathrm{~K} 1, \mathrm{~K} 2, \mathrm{~K} 3, \mathrm{~K} 4$ and $\mathrm{K} 5$ membranes.

\begin{tabular}{cccccc}
\hline $\begin{array}{c}\text { Fabricated } \\
\text { membrane }\end{array}$ & $\begin{array}{c}\text { Final thickness } \\
(\mu \mathrm{m})\end{array}$ & $\begin{array}{c}\text { Water content } \\
(\%)\end{array}$ & $\begin{array}{c}\text { Porosity } \\
(\%)\end{array}$ & $\begin{array}{c}\text { Water contact } \\
\text { angle }\left({ }^{\circ}\right)\end{array}$ & $\begin{array}{c}\text { Average water } \\
\text { flux }\left(\mathrm{l} \mathrm{m}^{-2} \mathrm{~h}^{-1}\right)\end{array}$ \\
\hline $\mathrm{K} 0$ & $268 \pm 1.2$ & $38.95 \pm 0.4$ & $51.42 \pm 0.4$ & $79.46 \pm 0.2$ & $12.42 \pm 0.4$ \\
$\mathrm{~K} 1$ & $283 \pm 1.4$ & $54.01 \pm 0.2$ & $68.36 \pm 0.4$ & $57.56 \pm 0.6$ & $18.21 \pm 0.2$ \\
$\mathrm{~K} 2$ & $287 \pm 2.0$ & $66.21 \pm 0.2$ & $79.68 \pm 0.4$ & $53.47 \pm 0.4$ & $23.21 \pm 0.5$ \\
$\mathrm{~K} 3$ & $288 \pm 2.4$ & $72.34 \pm 0.2$ & $80.12 \pm 0.4$ & $44.82 \pm 0.8$ & $28.48 \pm 0.4$ \\
$\mathrm{~K} 4$ & $291 \pm 2.0$ & $76.21 \pm 0.2$ & $82.42 \pm 0.4$ & $38.87 \pm 0.2$ & $29.12 \pm 0.6$ \\
$\mathrm{~K} 5$ & $292 \pm 1.4$ & $74.21 \pm 0.2$ & $81.36 \pm 0.4$ & $42.46 \pm 0.4$ & $28.61 \pm 0.2$ \\
\hline
\end{tabular}

\subsection{Adsorption Isotherms}

The adsorption isotherm indicates how the adsorption molecules distribute between the liquid phase and the solid phase when the adsorption process reaches an equilibrium states. ${ }^{44}$ Figure 4 shows the BSA adsorption isotherm or adsorption equilibrium of $\mathrm{K} 0, \mathrm{~K} 1, \mathrm{~K} 2, \mathrm{~K} 3, \mathrm{~K} 4$ and $\mathrm{K} 5$ membranes. The BSA adsorption capacity at equilibrium was found to increase with an increase in initial BSA concentration. When the initial concentration increases, the mass transfer driving 
force would become larger, hence resulting in higher BSA adsorption. Also, by increasing the HAP loading in fabricated membrane, the surface area and the number of sorption site would become large, hence enhancement in higher BSA adsorption capacity.

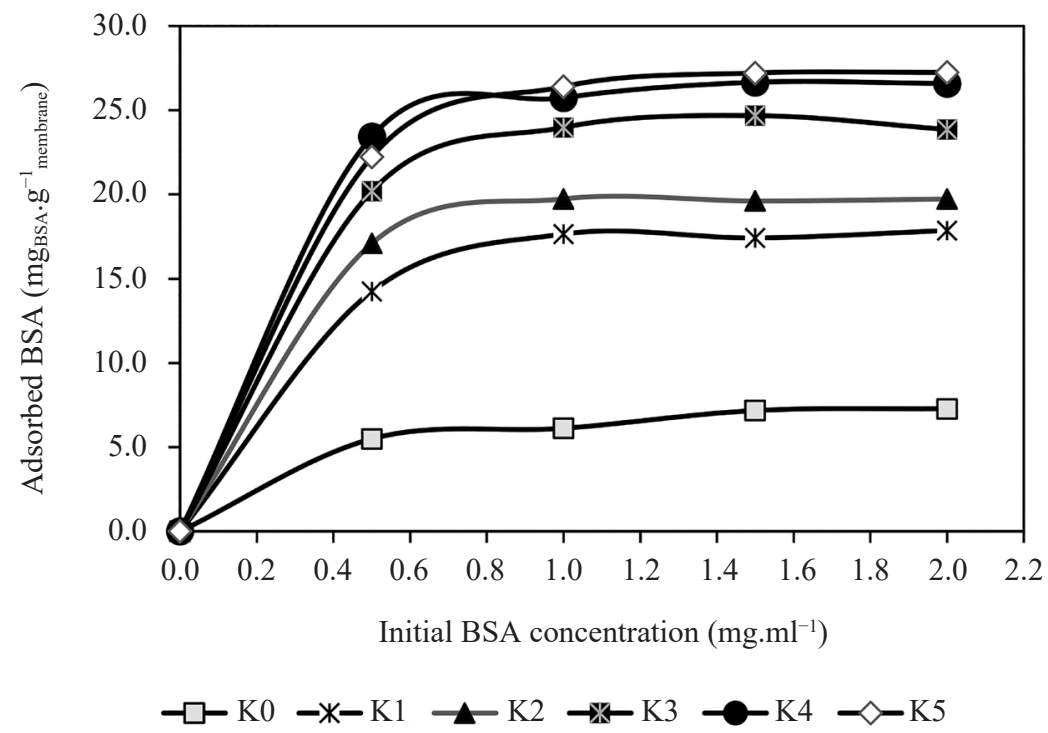

Figure 4: SA static adsorption of HAP onto K0, KI, K2, K3, K4 and K5 membranes.

In this study, the adsorption isotherm study was carried out using Langmuir and Freundlich isotherm model. The nonlinear regression of Langmuir and Freundlich model was solved using Polymath software. Table 3 summarises all the constant and $R^{2}$ value and RMSE for adsorption of BSA on K0, K1, K2, K3, K4 and K5 membranes. The Freundlich isotherm model yielded the best fit with the highest $R^{2}$ values which were close to unity compared with the Langmuir model. Conformation of the experimental data into Freundlich isotherm model indicated the formation of heterogeneous surface of fabricated membrane for BSA adsorption. The value of $1 / \mathrm{n}$ was ranged between 0 and 1 and gets closer to zero indicating that the surface of heterogeneity was increased with increasing amount of HAP. ${ }^{45}$ Among all the fabricated membranes (Figure 4), K4 and K5 showed the highest adsorption capacity followed by K3, K2, K1 and K0. This indicates that the increase in the amount of HAP makes more surface area available for BSA adsorption. However, based on Table 3, the maximum BSA adsorption capacities $\left(q_{e}\right)$ for $\mathrm{K} 4$ and $\mathrm{K} 5$ membranes were almost the same even the amount of HAP was increased from $60 \%$ up to $80 \%$. This shows that the active vacant sites available on the PES/HAP adsorptive MMM to adsorb all the BSA molecules at 
$2.0 \mathrm{mg} \mathrm{ml}^{-1}$ concentration reached the maximum range of vacant site to achieve the equilibrium. Besides physical properties, the high adsorption capacity of the fabricated adsorptive membrane was influenced by the presence of functional group such as calcium ion in HAP and hydroxyl group on their surfaces. Furthermore, higher BSA adsorption on fabricated membrane contain of HAP has been proved to be achieved by the electrostatic interaction on the surface between negatively charge $\mathrm{COOH}^{-}$group BSA and positively charge calcium ion of HAP. ${ }^{25}$

Table 3: Parameter values obtained from Langmuir and Freundlich isotherm for adsorption of BSA on K0, KI, K2, K3, K4 and K5 membranes.

\begin{tabular}{llccccc}
\hline Isotherm models constant & $\mathrm{K} 0$ & $\mathrm{~K} 1$ & $\mathrm{~K} 2$ & $\mathrm{~K} 3$ & $\mathrm{~K} 4$ & $\mathrm{~K} 5$ \\
\hline Langmuir isotherm & & & & & & \\
$\quad \mathrm{q}_{\mathrm{m}}\left(\mathrm{mg} \mathrm{g}^{-1}\right)$ & 9.64 & 17.76 & 19.15 & 24.51 & 26.67 & 26.66 \\
$\mathrm{~K}_{\mathrm{D}}\left(\mathrm{l} \mathrm{mg}^{-1}\right)$ & 4.22 & 5.64 & 6.12 & 9.46 & 10.08 & 8.99 \\
$\mathrm{R}^{2}$ & 0.992 & 0.991 & 0.990 & 0.993 & 0.992 & 0.991 \\
$\quad \mathrm{RMSE}$ & 8.81 & 9.23 & 9.48 & 8.80 & 8.82 & 9.24 \\
Freundlich isotherm & & & & & & \\
$\quad \mathrm{K}_{\mathrm{F}}\left(\mathrm{mg} \mathrm{g}^{-1}\left(\mathrm{mg}^{-1}\right)^{1 / \mathrm{n}}\right)$ & 6.33 & 16.49 & 18.83 & 22.84 & 25.33 & 25.33 \\
$\quad 1 / \mathrm{n}$ & 0.23 & 0.15 & 0.12 & 0.11 & 0.09 & 0.08 \\
$\mathrm{n}$ & 4.35 & 6.67 & 8.33 & 9.09 & 11.11 & 12.5 \\
$\mathrm{R}^{2}$ & 0.999 & 0.998 & 0.999 & 0.999 & 0.997 & 0.999 \\
$\mathrm{RMSE}$ & 5.47 & 5.68 & 5.12 & 4.12 & 6.01 & 6.14 \\
\hline
\end{tabular}

\subsection{Kinetic Studies}

The kinetics of adsorption describes the rate of adsorbate uptake onto the fabricated adsorptive MMM, and thus it controls the equilibrium time. Figure 5 shows the kinetics plots of the experimental data for the adsorption of BSA onto $\mathrm{K} 0, \mathrm{~K} 1, \mathrm{~K} 2, \mathrm{~K} 3, \mathrm{~K} 4$ and $\mathrm{K} 5$ membranes. For all the fabricated membranes, it is clear from the graph that the amount of BSA adsorbed increased with time and at some point in time, the adsorption became slower and reached the equilibrium state. This phenomenon was due to the fact that a larger number of vacant surface sites available for BSA adsorption during the initial stage, and after a lapse time, the remaining vacant surface sites were difficult to be occupied due to repulsive forces between BSA solute molecule on the solid and bulk phases. ${ }^{36,46}$ The amount of the BSA adsorbed at the equilibrium time reflected the maximum adsorption capacity of the adsorbent under the operation condition applied. The BSA adsorption equilibrium was found to increase with an increase in the HAP amount. This indicated that the active vacant sites available on the fabricated membrane were sufficient to adsorb all the BSA molecules at these range of HAP loading. 


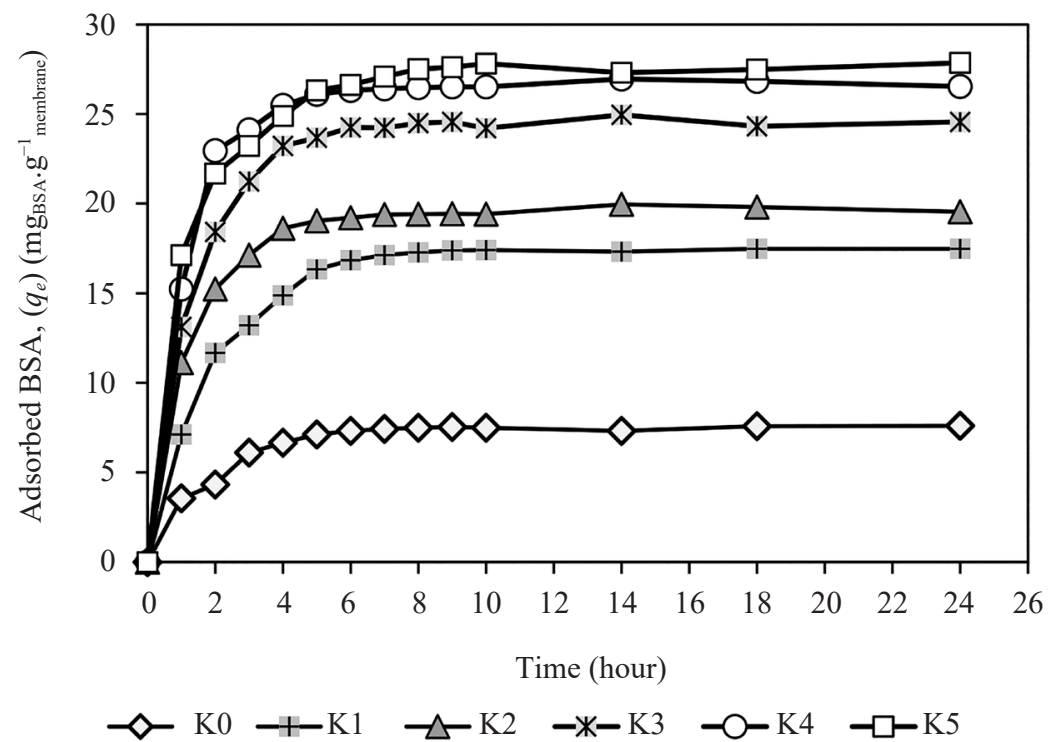

Figure 5: Kinetic adsorption of HAP onto K0, KI, K2, K3, K4 and K5 membrane.

In this study, pseudo-first-order kinetic model and pseudo-second-order kinetic model were applied to study the kinetics of adsorption process. The kinetics data were analysed, and the constants were computed using Microsoft Excel. Fitting results for the kinetic models are given in Table 4. The results showed that the pseudo-second-order fitted well with the kinetic data and showed the excellent goodness of fit $\left(R^{2}\right)$. Pseudo-first-order kinetic model also gave an acceptable fit to the kinetic data with $R^{2}$ more than 0.990 and less RMSE value. The equilibrium adsorption capacity estimated by the pseudo-second-order was comparable with the experimental ones (Table 4). The adsorption kinetic rate constant $\left(\mathrm{k}_{2}\right)$ increases as a result of the HAP loading from $10 \%$ to $60 \%$ and the $\mathrm{k}_{2}$ was slightly decreased at $80 \%$ of HAP. This indicates that, the BSA adsorption rate onto the fabricated membranes is more rapid and favourable at $10 \%$ to $60 \%$ of HAP contents. The relatively high adsorption rate and value of fabricated membrane were due to their relatively high surface area and influenced by its surface chemistry. The functional group of HAP on the surface of fabricated membrane could act as chemical binding agents and hence attributed to the electrostatic interaction between positively charge calcium ion of HAP and negatively charge $\mathrm{COOH}^{-}$group BSA. 
Table 4: Parameter values of pseudo-first and pseudo-second-order kinetic models for adsorption of BSA on K0, KI, K2, K3, K4 and K5 membranes.

\begin{tabular}{|c|c|c|c|c|c|}
\hline \multirow[b]{2}{*}{ Membrane } & \multirow{2}{*}{$\begin{array}{c}\text { Experiment } \mathrm{q}_{\text {exp }} \\
\left(\mathrm{g} \mathrm{BSA} \mathrm{g}^{-1} \text { membrane }^{-1}\right)\end{array}$} & \multicolumn{4}{|c|}{ Pseudo-first-order kinetic model } \\
\hline & & $\begin{array}{c}\mathrm{q}_{\mathrm{eq} 1} \\
\left(\mathrm{~g} \mathrm{BSA} \mathrm{g}^{-1} \text { membrane }^{-1}\right)\end{array}$ & $\mathrm{k}_{1}\left(\mathrm{~h}^{-1}\right)$ & $\mathrm{R}^{2}$ & $\begin{array}{c}\text { RMSE } \\
(\%)\end{array}$ \\
\hline K0 & 7.68 & 7.71 & 0.514 & 0.991 & 8.45 \\
\hline $\mathrm{K} 1$ & 17.48 & 19.10 & 0.552 & 0.993 & 7.12 \\
\hline $\mathrm{K} 2$ & 19.54 & 24.14 & 0.649 & 0.994 & 6.41 \\
\hline K3 & 24.95 & 24.21 & 0.773 & 0.991 & 6.27 \\
\hline K4 & 26.54 & 26.15 & 0.814 & 0.991 & 6.25 \\
\hline K5 & 26.66 & 26.24 & 0.697 & 0.992 & 6.48 \\
\hline \multirow[b]{2}{*}{ Membrane } & \multicolumn{5}{|c|}{ Pseudo-second-order kinetic model } \\
\hline & $\begin{array}{c}\mathrm{q}_{\mathrm{eq} 2} \\
\left(\mathrm{~g} \mathrm{BSA} \mathrm{g}^{-1} \text { membrane }^{-1}\right)\end{array}$ & $\begin{array}{c}\mathrm{k}_{2} \\
\left(\mathrm{~g} \text { membrane } \mathrm{g}^{-1} \mathrm{BSA}^{-1} \mathrm{~h}^{-1}\right)\end{array}$ & $\mathrm{R}^{2}$ & \multicolumn{2}{|c|}{ RMSE (\%) } \\
\hline K0 & 7.89 & 0.049 & 0.999 & \multicolumn{2}{|c|}{2.12} \\
\hline K1 & 18.15 & 0.078 & 0.996 & \multicolumn{2}{|c|}{3.85} \\
\hline K2 & 20.00 & 0.149 & 0.998 & \multicolumn{2}{|c|}{3.23} \\
\hline $\mathrm{K} 3$ & 25.06 & 0.153 & 0.999 & \multicolumn{2}{|c|}{2.18} \\
\hline K4 & 27.13 & 0.158 & 0.998 & \multicolumn{2}{|c|}{3.31} \\
\hline K5 & 27.11 & 0.069 & 0.999 & \multicolumn{2}{|c|}{2.24} \\
\hline
\end{tabular}

\subsection{Regeneration}

The regeneration of $\mathrm{K} 0, \mathrm{~K} 1, \mathrm{~K} 2, \mathrm{~K} 3, \mathrm{~K} 4$ and $\mathrm{K} 5$ membranes were carried out in this study by using acetate buffer solution at $\mathrm{pH} 4.2$. The membranes were soaked into acetate buffer solution for $24 \mathrm{~h}$ with shaking speed at $90 \mathrm{rpm}$ in room temperature. The regeneration process was repeated for three cycles. The results of the adsorption and regeneration cycles are shown in Figure 6. After three regeneration cycles, there has been a significant reduction in BSA adsorption capacity ( $28 \%$ loss) of the K1 membrane. Among all PES/HAP adsorptive membrane, $\mathrm{K} 4$ membrane shows less reduction in the BSA adsorption capacity after three cycle of regeneration was about $1.58 \%$. This is followed by $\mathrm{K} 3, \mathrm{~K} 2$, K1 and K5 which were about $3.01 \%, 4.76 \%, 9.72 \%$ and $14.5 \%$, respectively. This clearly indicates that the fabricated PES/HAP adsorptive MMM (K4 membrane) has good regeneration and reusability characteristic for the BSA adsorption. 


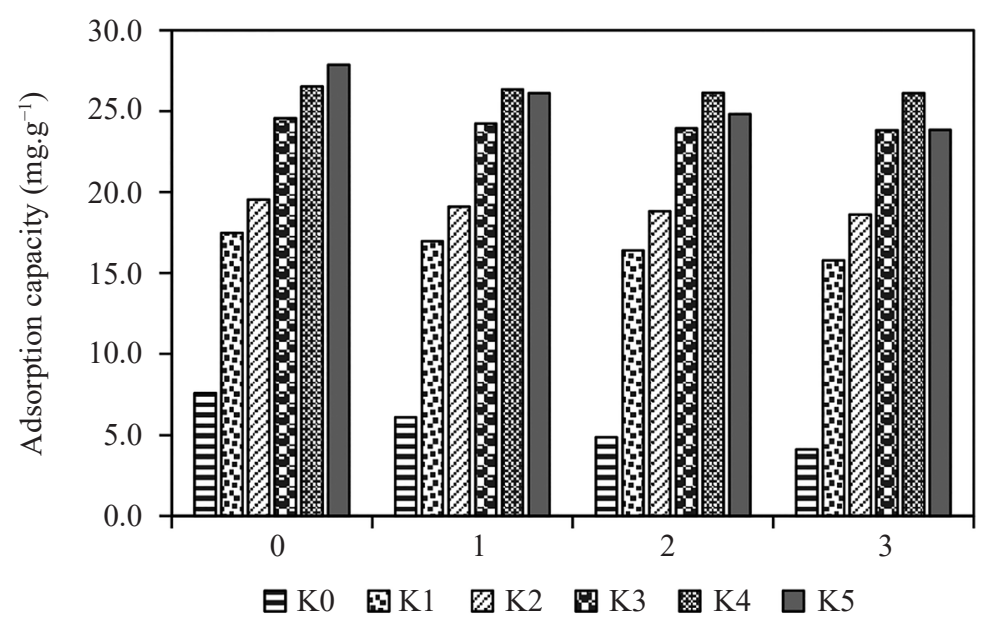

Figure 6: Adsorption/regeneration cycles for K0, K1, K2, K3, K4 and K5.

\section{CONCLUSION}

In this study, HAP was used to introduce cationic functionalities in the PES matrix membrane. The PES/HAP adsorptive MMM shows better resets for adsorption of BSA due to membrane structure, hydrophilic nature, permeability balance and electrostatic interaction between positively charge calcium ion of HAP and negatively charge $\mathrm{COOH}$ group BSA. The membrane adsorption was significantly affected by different amount of HAP loading in the casting solution. Among all prepared membranes, K4 showed an enhanced BSA adsorption capacity with higher adsorption rate and good reusability. Freundlich isotherm model is the best fitted to describe BSA adsorption process on PES/HAP adsorptive MMM. The kinetic of the adsorption process is well presented by pseudo-second-order kinetic model. It can be concluded that PES/HAP adsorptive MMM offered high potential merit for application in membrane adsorption processes especially in protein purification technology.

\section{ACKNOWLEDGEMENTS}

The authors acknowledge the financial support provided by Universiti Sains Malaysia under the Postdoctoral Fellowship Scheme and Research University (RU) Membrane Science and Technology Cluster. Acknowledgement is also extended to the Ministry of Higher Education (MOHE) Malaysia for the Fundamental Research Grant Scheme (FRGS) (grant no: 203/PJKIMIA/6071334) and Long Term Research Grant Scheme (LRGS) (grant no: 203/PJKIMIA/6727101). 


\section{REFERENCES}

1. Levison, P. R. (2003). Large-scale ion-exchange column chromatography of proteins: Comparison of different formats. J. Chromatogr. B, 790, 17-33, https://doi.org/10.1016/S1570-0232(03)00087-4.

2. Chase, H. A. (1994). Purification of proteins by adsorption chromatography in expanded beds. Trends Biotechnol., 12, 296-303, https://doi.org/10.1016/01677799(94)90046-9.

3. Gerberding, S. J. \& Byers, C. (1998). Preparative ion-exchange chromatography of proteins from dairy whey. J. Chromatogr. A, 808, 141-151, https://doi.org/ 10.1016/S0021-9673(98)00103-4.

4. Moore, S. et al. (1958). Chromatography of amino acids on sulfonated polystyrene resins: An improved system. Anal. Chem., 30, 1185-1190, https://doi. org/10.1021/ac60139a005.

5. Cao, L. (2005). Protein separation with ion-exchange membrane chromatography. MA diss., Worcester Polytechnic Institute, Massachusetts, United States.

6. Lin, C.-H. et al. (2014). Preparation of polyethersulfone/plant-waste-particles mixed matrix membranes for adsorptive removal of cationic dyes from water. J. Membr. Sci., 471, 285-298, https://doi.org/10.1016/j.memsci.2014.08.003.

7. Huang, H.-J. et al. (2008). A review of separation technologies in current and future biorefineries. Sep. Purif. Technol., 62, 1-21, https://doi.org/10.1016/j. seppur.2007.12.011.

8. Saxena, A. et al. ( 2009). Membrane-based techniques for the separation and purification of proteins: An overview. Adv. Coll. Interf. Sci., 145, 1-22, https://doi.org/10.1016/j.cis.2008.07.004.

9. Ghosh, R. (2002). Protein separation using membrane chromatography: Opportunities and challenges. J. Chromatogr. A, 952, 13-27, https://doi.org/10. 1016/S0021-9673(02)00057-2.

10. Suen, S.-Y. (2015). Mixed matrix membranes for adsorption application. J. Chem. Eng. Proc. Technol., 6, 1-9.

11. Thömmes, J. \& Kula, M. R. (1995). Membrane chromatography: An integrative concept in the downstream processing of proteins. Biotechnol. Progr., 11, 357-367, https://doi.org/10.1021/bp00034a001.

12. Tennikova, T. et al. (1991). High-performance membrane chromatography of proteins, a novel method of protein separation. J. Chromatogr. A, 555, 97-107, https://doi.org/10.1016/S0021-9673(01)87170-3.

13. Avramescu, M.-E. et al. (2003). Preparation of mixed matrix adsorber membranes for protein recovery. J. Membr. Sci., 218, 219-233, https://doi.org/ 10.1016/S0376-7388(03)00178-9.

14. Zhang, F.-1. et al. (2009). Adsorption of bovine hemoglobin on EVAL hollow fiber membrane filled with strongly acidic macroporous cation exchange resins. J. Tianj. Polytech. Uni., 28(2), 10-13. 
15. Zhang, Y. Z. et al. (2006). Adsorption behavior of cation-exchange resin-mixed polyethersulfone-based fibrous adsorbents with bovine serum albumin. Desalin., 192, 224-233, https://doi.org/10.1016/j.desal.2005.06.048.

16. Zeng, X. \& Ruckenstein, E. (1999). Membrane chromatography: Preparation and applications to protein separation. Biotechnol. Progr., 15, 1003-1019, https://doi.org/10.1021/bp990120e.

17. Briefs, K.-G. \& Kula, M.-R. (1992). Fast protein chromatography on analytical and preparative scale using modified microporous membranes. Chem. Eng. Sci., 47, 141-149, https://doi.org/10.1016/0009-2509(92)80208-T.

18. Saufi, S. M. \& Fee, C. J. (2013). Mixed matrix membrane chromatography based on hydrophobic interaction for whey protein fractionation. J. Membr. Sci., 444, 157-163, https://doi.org/10.1016/j.memsci.2013.05.007.

19. Shoparwe, N. F. et al. (2018). Fabrication, characterisation and electrochemical properties of heterogeneous multiwalled carbon nanotubes cation exchange membranes (MWCNT-CEMs). J. Phys. Sci., 29(Supp. 1), 41-48, https://doi.org/ 10.21315/jps2018.29.s1.6.

20. Salehi, E. et al. (2012). Novel chitosan/poly (vinyl) alcohol thin adsorptive membranes modified with amino functionalized multi-walled carbon nanotubes for $\mathrm{Cu}$ (II) removal from water: Preparation, characterization, adsorption kinetics and thermodynamics. Sep. Purif. Technol., 89, 309-319, https://doi.org/10.1016/j. seppur.2012.02.002.

21. Ahmad, A. L. \& Shafie, Z. M. H. M. (2017). Effect of air gap distance on PES/ PVA hollow fibre membrane's morphology and performance. J. Phys. Sci., 28(Supp. 1), 185-199, https://doi.org/10.21315/jps2017.28.s1.12.

22. Ngang, H. et al. (2017). Preparation of PVDF-TiO2 mixed-matrix membrane and its evaluation on dye adsorption and UV-cleaning properties. Chem. Eng. J., 197, 359-367, https://doi.org/10.1016/j.cej.2012.05.050.

23. Sun, J. \& Wu, L. (2014). Adsorption of protein onto double layer mixed matrix membranes. Coll. Surf. B Biointerf., 123, 33-38, https://doi.org/10.1016/j. colsurfb.2014.09.006.

24. Hayder, A. et al. (2017). Fabrication and characterization of cellulose acetate/ hydroxyapatite composite membranes for the solute separations in hemodialysis. Polym. Bull.,12, 1-14.

25. Sun, J. \& Chen, J. (2015). Mixed matrix membranes embedding modified hydroxyapatite for protein adsorption. Paper presented at the Asia Pacific Confederation of Chemical Engineering Congress 2015 (APCChE 2015), Melbourne, 2284.

26. Ciobanu, G. \& Ciobanu, O. (2016). High-performance ultrafiltration mixed-matrix membranes based on cellulose acetate and nanohydroxyapatite. Desalin. Wat. Treat., 57, 23257-23265, https://doi.org/10.1080/19443994.2015.1108428.

27. Sun, J. et al. (2015). Polyvinylidene fluoride/silane-treated hydroxyapatite mixed matrix membrane for enzyme capturing. Coll. Surf. B Biointerf., 126, 265-272, https://doi.org/10.1016/j.colsurfb.2014.12.034. 
28. Suchanek, W. \& Yoshimura, M. (1998). Processing and properties of hydroxyapatite-based biomaterials for use as hard tissue replacement implants. J. Mater. Res., 13, 94-117, https://doi.org/10.1557/JMR.1998.0015.

29. Cüneyt Tas, A. (2000). Synthesis of biomimetic Ca-hydroxyapatite powders at $37^{\circ} \mathrm{C}$ in synthetic body fluids. Biomater., 21, 1429-1438.

30. Yin, G. Z. et al. (2002). Impacts of the surface charge property on protein adsorption on hydroxyapatite. Chem. Eng. J., 87, 181-186, https://doi.org/10.1016/ S1385-8947(01)00248-0.

31. Wassell, D. T. et al. (1995). Adsorption of bovine serum albumin onto hydroxyapatite. Biomater., 16, 697-702, https://doi.org/10.1016/0142-9612(95) 99697-K.

32. Swain, S. K. \& Sarkar, D. (2013). Study of BSA protein adsorption/release on hydroxyapatite nanoparticles. Appl. Surf. Sci., 286, 99-103, https://doi.org/ 10.1016/j.apsusc.2013.09.027.

33. Mavropoulos, E. et al. (2011). Adsorption and bioactivity studies of albumin onto hydroxyapatite surface. Coll. Surf. B Biointerf., 83, 1-9, https://doi.org/ 10.1016/j.colsurfb.2010.10.025.

34. Shimabayashi, S. et al. (1991). Effect of phosphorylated organic compound on the adsorption of bovine serum albumin by hydroxyapatite. Chem. Pharm. Bull., 39, 2183-2188, https://doi.org/10.1248/cpb.39.2183.

35. Shoparwe, N. F. et al. (2018). Fouling evaluation of polyethersulfone (PES)/ sulfonated cation exchange resin (SCER) membrane for BSA separation. J. Appl. Polym. Sci., 135, 45854, https://doi.org/10.1002/app.45854.

36. Foo, K. \& Hameed, B. (2010). Insights into the modeling of adsorption isotherm systems. Chem. Eng. J., 156, 2-10, https://doi.org/10.1016/j.cej.2009.09.013.

37. Veith, J. \& Sposito, G. (1977). On the use of the Langmuir equation in the interpretation of "adsorption" phenomena. Soil Sci. Soc. Am. J., 41, 697-702, https://doi.org/10.2136/sssaj1977.03615995004100040015x.

38. Jones, K. L. \& O’Melia, C. R. (2000). Protein and humic acid adsorption onto hydrophilic membrane surfaces: Effects of $\mathrm{pH}$ and ionic strength. J. Membr. Sci., 165, 31-46, https://doi.org/10.1016/S0376-7388(99)00218-5.

39. Redlich, O. \& Peterson, D. L. (1959). A useful adsorption isotherm. J. Phys. Chem., 63, 1024-1024, https://doi.org/10.1021/j150576a611.

40. Pignatello, J. J. \& Xing, B. (1995). Mechanisms of slow sorption of organic chemicals to natural particles. Environ. Sci. Technol., 30, 1-11, https://doi.org/ 10.1021/es940683g.

41. Ho, Y. \& McKay, G. (1998). A comparison of chemisorption kinetic models applied to pollutant removal on various sorbents. Proc. Safety Environ. Protect., 76, 332-340, https://doi.org/10.1205/095758298529696.

42. Lau, W. \& Ismail, A. (2009). Theoretical studies on the morphological and electrical properties of blended PES/SPEEK nanofiltration membranes using different sulfonation degree of SPEEK. J. Membr. Sci., 334, 30-42, https://doi. org/10.1016/j.memsci.2009.02.012. 
43. Nagasaki, T. et al. (2017). Effects of pore distribution of hydroxyapatite particles on their protein adsorption behavior. J. Asian Ceram. Soc., 5(2), 88-93, https://doi.org/10.1016/j.jascer.2017.01.005

44. Ruthven, D. M. (1984). Principles of adsorption and adsorption processes. New York: John Wiley \& Sons.

45. Tan, I. et al. (2008). Adsorption of basic dye on high-surface-area activated carbon prepared from coconut husk: Equilibrium, kinetic and thermodynamic studies. J. Hazard. Mater., 154, 337-346, https://doi.org/10.1016/j.jhazmat.2007.10.031.

46. Santos, L. et al. (2016). Adsorption of peroxidase from Raphanus sativus L onto alginate-guar gum matrix: Kinetic, equilibrium and thermodynamic analysis. Adsorp. Sci. Technol., 34, 388-402, https://doi.org/10.1177/0263617416659287. 